\title{
CRÉDITO RURAL E SUSTENTABILIDADE: UM ESTUDO COMPARATIVO EM PEQUENAS PROPRIEDADES RURAIS
}

\author{
RURAL CREDIT AND SUSTAINABILITY: A COMPARATIVE STUDY ON SMALL RURAL PROPERTIES
}

\author{
CAROLINA OPUCHKEVITCH | UNICENTRO \\ ALDO SIATKOWSKI | UNICENTRO \\ FLAVIA MASSUGA, M.SC. | UNICENTRO \\ MAURICIO JOÃO ATAMANCZUK, Dr. | UNICENTRO
}

\begin{abstract}
RESUMO
Diante da crescente demanda mundial por alimentos, a agricultura familiar e o acesso ao crédito rural têm sido entendidos como fatores essenciais para o desenvolvimento do setor agrícola de forma sustentável. Baseandose nesse contexto, este estudo teve como objetivo identificar a relação do crédito rural com o desenvolvimento sustentável de pequenas propriedades agrícolas no município de Prudentópolis-PR, comparando propriedades tomadoras e não tomadoras de crédito rural em relação ao atendimento das dimensões econômica, ambiental e social da sustentabilidade. Para tanto, foi realizada uma pesquisa de campo, a partir de entrevistas e observações, em 6 propriedades rurais, sendo 3 tomadoras de crédito rural e 3 não tomadoras. Os resultados demonstram que o crédito rural é uma ferramenta essencial para o desenvolvimento das propriedades rurais. Apesar do não conhecimento sobre a aplicação do conceito de sustentabilidade, por parte dos agricultores, diferenças são identificadas nas dimensões econômica e social. De modo geral, os resultados demonstram que propriedades tomadoras de crédito rural apresentam mais medidas de desenvolvimento sustentável em relação as não tomadoras de crédito, denotando o crédito rural como uma importante ferramenta que pode auxiliar em uma produção agrícola mais sustentável.
\end{abstract}

PALAVRAS CHAVE: Agricultura familiar; Crédito rural; Desenvolvimento sustentável.

\begin{abstract}
In view of the growing world demand for food, family farming and access to rural credit have been understood as essential factors for the sustainable development of the agricultural sector. Based on this context, this study aimed to identify the relationship between rural credit and the sustainable development of small agricultural properties in the municipality of Prudentópolis-PR comparing rural borrowing and non-borrowing properties in relation to meeting the economic, environmental and social dimensions of sustainability. For that, a field research was carried out, from interviews and observations, in 6 rural properties, being 3 rural credit borrowers and 3 non-borrowers. The results demonstrate that rural credit is an essential tool for the development of rural properties. Despite farmers' lack of knowledge about the application of the concept of sustainability, differences are identified in the economic and social dimensions. In general, the results demonstrate that rural credit borrowing properties have more sustainable development measures than non-credit borrowers, denoting rural credit as an important tool that can assist in more sustainable agricultural production.
\end{abstract}

KEY WORDS: Family farming; Rural credit; Sustainable development. 


\section{INTRODUÇÃO}

Estima-se um aumento populacional para 9,8 bilhões de habitantes em 2050, o que acarretará uma elevação na demanda por alimentos e fará com que o setor do agronegócio se torne cada vez mais relevante (ORGANIZAÇÃO DAS NAÇÕES UNIDAS [ONU], 2017). Contudo, um dos grandes desafios globais de segurança alimentar é a necessidade de estimar de forma confiável a demanda futura de alimentos considerando uma população mundial cada vez mais numerosa, mais urbana, mais educada, rica e exigente que pressionará a produção e sofisticação destes alimentos até 2050 (LOPES, 2018). Segundo dados divulgados pela Food and Agriculture Organization (FAO, 2017), é esperado um aumento de $70 \%$ da produção mundial de alimentos, a fim de atender ao acréscimo de demanda, sem resultar em escassez ou alteração nos preços.

Nesse cenário, o Brasil pode ser protagonista. Com o setor do agronegócio brasileiro cada vez mais preparado para atender à crescente demanda, o país pode tornar-se o principal fornecedor de alimentos a nível mundial. Segundo a FAO (2019), as perspectivas são que na próxima década o Brasil possa ser o país com maior volume de produção e exportação agropecuária do mundo, resultado, dentre outros fatores, do aumento de políticas públicas para auxiliar no desenvolvimento do setor, da expansão de territórios agricultáveis e das inovações constantes no desenvolvimento de novas ferramentas para o aumento da produtividade.

Nesse contexto de expansão, a importância da agricultura familiar na produção de alimentos é inquestionável (PAULA FILHO; CALVI; CASTRO, 2016). Segundo a FAO (2017), tanto em países em desenvolvimento, como em nações desenvolvidas, a produção de pequenos produtores é a forma predominante na produção de alimentos, sendo que cerca de $70 \%$ dos alimentos que chegam às mesas são provenientes das mãos dos pequenos agricultores. Além dos aspectos de eficiência voltado para a produção em pequenas propriedades rurais, Blowfield (2013) destaca como desafio, produzir alimentos suficientes de maneira que não comprometam questões da sustentabilidade como energia, água e pobreza, uma vez que já existem indícios de que as mudanças climáticas, embora possam aumentar os rendimentos de algumas áreas, resultarão de forma global em redução de produção alimentícia ao longo do tempo.

Para desenvolver o setor agrícola de forma sustentável, especialmente em países em desenvolvimento, Ogundeji et al. (2018) sugerem a necessidade de investimentos de capital por meio do acesso adequado ao crédito rural. O crédito rural consiste em serviços de crédito em áreas rurais que visam famílias de todos os níveis de renda (LINH et al., 2019). Dados poucos recursos capazes de suprir a demanda financeira para custear a produção agrícola, a disponibilidade de crédito rural vem impulsionando o setor do agronegócio brasileiro, no que se refere ao incremento da produção, especialmente das pequenas propriedades.

Segundo Linh et al. (2019), o acesso ao crédito tem um enorme impacto socioeconômico nas famílias rurais, contribuindo com o aumento da produção, melhoria da renda familiar e, consequentemente, redução da pobreza. Além disso, o acesso ao crédito aumenta a capacidade dos agricultores rurais atenderem às suas necessidades financeiras, tais como, compra de insumos agrícolas e realização de demais investimentos produtivos (LIN et al., 2019).

Para a Organização para a Cooperação e Desenvolvimento Econômico (OECD, 2015), Asante-Addo et al. (2017) e Oseni, Babalola e Adesoye (2019), o desenvolvimento agrícola conciliado com o crédito rural está diretamente ligado com a sustentabilidade. Conforme Delgado e Bergamasco (2017), as propriedades tomadoras de crédito rural possuem maior desenvolvimento diante das não tomadoras, pois sua qualidade de vida aumenta e o desenvolvimento sustentável ocorre de maneira mais efetiva. Sobre a questão, Santos e Cedraz (2015) destacam ainda que o crédito rural não resolve somente entraves relacionados a escassez de recursos financeiros, mas também é capaz de propagar o desenvolvimento local de uma comunidade de agricultores familiares associado com o desenvolvimento sustentável.

Dado o contexto brasileiro em que a disponibilidade de crédito rural vem impulsionando o agronegócio brasileiro, considerando principalmente pequenas propriedades, e tendo presumido a relação da disponibilidade de crédito com a sustentabilidade, este estudo apresenta como objetivo principal identificar na prática a relação do crédito rural com o desenvolvimento sustentável de pequenas propriedades agrícolas no município de Prudentópolis-PR. Para isso, são comparadas propriedades tomadoras e não tomadoras de crédito rural no que concerne ao atendimento das dimensões econômica, ambiental e social da sustentabilidade. A escolha do município deve-se ao fato de grande parte da população residir em zonas rurais, sendo $54 \%$, conforme último censo realizado. Além disso, a agropecuária destaca-se como um setor bastante representativo, correspondendo a $34,82 \%$ do PIB municipal (IBGE, 2020).

Além desta seção de introdução o artigo discorre sobre os elementos teóricos balizadores da análise na seção 2, esclarece os procedimentos metodológicos adotados na 
seção 3, apresenta os resultados e discussões do trabalho de campo na seção 4 e sintetiza reflexões sobre os resultados alcançados na seção 5 . Ainda são citadas as referências bibliográficas utilizadas para embasamento do estudo.

\section{FUNDAMENTAÇÃO TEÓRICA}

\subsection{Crédito rural}

O agronegócio desempenha um papel importante no processo de desenvolvimento econômico de um país e é crucial para a segurança alimentar interna, assim como, para o crescimento do emprego e redução da pobreza (OGUNDEJ et al., 2018; LINH et al., 2019). Ele refere-se a um conjunto de atividades que envolvem desde o processo de fabricação e fornecimento de insumos, a produção, o processamento, o armazenamento até a distribuição para o consumo interno e internacional dos produtos oriundos da agricultura e pecuária. Esse processo envolve também as formas de financiamento que são disponibilizadas para que esta produção ocorra.

O crédito rural é uma das várias maneiras de se subsidiar a agricultura brasileira, auxiliando no desenvolvimento de produtores rurais que não possuem recursos financeiros para gerir sua propriedade e a produção. Para Ogundeji et al. (2018), o financiamento de custeios e investimentos é um componente importante dos programas de desenvolvimento agrícola e rural, sendo um instrumento de auxílio a pequenos agricultores para aumentar sua renda e a qualidade de vida das famílias. Espera-se que o acesso ao crédito contribua com a capacidade das famílias de adquirir tecnologias para melhorar atividades agrícolas e investir no cultivo de culturas de alto rendimento (OSENI; BABALOLA; ADESOYE, 2019). Nesse sentido, compreende-se que o crédito rural associa o bem-estar de pessoas que residem no meio rural e o crescimento do setor do agronegócio (GRISA; SCHNEIDER, 2015).

Devido a estes benefícios, diversos programas foram estabelecidos para a disponibilização de crédito rural. No Brasil o Banco Central (BC) é o responsável pela gestão do Sistema Nacional de Crédito Rural (SNCR), bem como, das instituições financeiras que concedem os financiamentos. Segundo o BC (2020), o crédito visa custear despesas normais dos ciclos produtivos e contribuir com investimentos, comercialização e industrialização. Dentre os programas nacionais de crédito destacam-se o Programa Nacional de Fortalecimento da Agricultura Familiar (PRONAF), o qual destina-se especialmente para agricultores familiares e assentados da reforma agrária; o Plano Safra, que auxilia agricultores a custear a safra e investir; e o Programa de Garantia da Atividade Agropecuária (PROAGRO) que garante o pagamento de financiamentos rurais de custeio agrícola, caso a lavoura sofra redução de receita devido a eventos climáticos ou pragas (BANCO CENTRAL DO BRASIL, 2020).

Diante do contexto do agronegócio brasileiro, o governo tem procurado ampliar o fornecimento de crédito rural para a agricultura familiar como uma forma de inclusão socioeconômica, gerando impactos significativos na melhoria da qualidade de vida de produtores rurais (DELGADO; BERGAMASCO, 2017). No entanto, ainda existem algumas dificuldades no acesso ao crédito no que se refere a exigências de garantias pelas instituições financeiras (PAULA FILHO; CALVI; CASTRO, 2016). Além disso, para o acesso ao crédito é necessário que o agricultor atenda a algumas exigências exemplificadas no Manual de Crédito Rural (BANCO CENTRAL DO BRASIL, 2020a), as quais não são possíveis de serem alcançadas por todos que pleiteiam o uso deste instrumento financeiro, reduzindo a capacidade de financiamento da produção e de investimentos.

Segundo Linh et al. (2019), fatores socioeconômicos também impactam a acessibilidade ao crédito dos agricultores, tais como idade, tamanho da família, renda, educação, gênero e tamanho das propriedades. Lin et al. (2019) complementam esse entendimento ao afirmar que o histórico de empréstimos informais tem influência significativa sobre a restrição de crédito, assim como, níveis mais altos de educação são menos propensos a sofrer restrições. Por outro lado, a decisão dos agricultores sobre a utilização de crédito está associada a fatores que incluem o tamanho da família, o uso de mão-de-obra contratada, associação em cooperativas, conhecimento sobre as fontes de crédito, montante de empréstimos passados, posse de garantias e proximidade com a instituição de crédito (ASANTE-ADDO, et al., 2017; OSENI; BABALOLA; ADESOYE, 2019).

Dados os riscos associados, a fiscalização e o acompanhamento da operação de créditos são fundamentais para a liquidez das instituições financeiras. Além disso, para atender esse preceito, a busca pela redução de inconformidades de informações antes à concessão do crédito é responsável por garantir baixa inadimplência dos diversos programas (MARAJÓ; PLÁCIDO JÚNIOR, 2019).

Apesar da existência de algumas restrições, não há dúvidas sobre a importância do acesso ao crédito a pequenos produtores para o avanço do agronegócio no Brasil. Além disso, dada a crescente demanda por alimentos e preocupações ambientais associadas, há uma necessidade de ênfase para políticas agrícolas, inclusive às relacionadas ao fornecimento de crédito rural, que atendam aos 
critérios de sustentabilidade, assumindo um papel que proporcione aumento da riqueza do país, mantendo a igualdade social e a proteção ao meio ambiente.

\subsection{Sustentabilidade em propriedades rurais}

No atual contexto que envolve a produção agropecuária e as questões ambientais é imprescindível que propriedades rurais organizem seus processos baseados no desenvolvimento sustentável, uma vez que, empregam recursos naturais que, se utilizados de maneira errônea, se findarão. Os três pilares de sustentabilidade, que devem ser seguidos pelas propriedades rurais, consideram agregar valor econômico na comunidade, desenvolvendo o meio social e reduzindo os impactos ambientais, para que as próximas gerações possam utilizar dos recursos disponíveis atualmente (EMPRESA BRASILEIRA DE PESQUISA AGROPECUÁRIA [EMBRAPA], 2018).

A sustentabilidade com ênfase na dimensão econômica, consiste em uma condição necessária para o desenvolvimento de propriedades rurais, pois é conforme sua rentabilidade que estes produtores rurais terão recursos financeiros necessários para investimentos em tecnologias sustentáveis em sua produção. LIN et al. (2019) confirmam essa compreensão ao afirmar que as escolhas de investimentos e crescimento dos produtores rurais são limitadas pelo nível de produção e empréstimo disponíveis a eles. No pilar econômico é possível identificar um elevado grau de dificuldade de obtenção de recursos financeiros no grupo dos agricultores rurais. Segundo Delgado e Bergamasco (2017), agricultores que possuem pequenas propriedades rurais sentem mais dificuldades em adquirir empréstimos se comparado aos grandes proprietários. Isso ocorre devido à falta de garantias suficientes (LINH et al., 2019). Para o Centro de Gestão e Estudos Estratégicos (CGEE, 2013) há uma disparidade em investimentos tecnológicos de pequenas para grandes propriedades rurais, podendo perceber que os recursos financeiros são um diferencial para que se tenha desenvolvimento em uma propriedade por meio de inovações, aquisição de terras e maquinários para agregar valor na produção.

A dimensão ambiental está atrelada aos efeitos derivados de atividades agropecuárias prejudiciais aos recursos naturais. Está associada com a preservação da água, solo, vegetação e a correta utilização de manejo, por exemplo (SILVA et al., 2016). É importante salientar que, no setor do agronegócio, as preocupações ambientais não exigem atenção somente nas atividades de produção, mas também enfoca o planejamento de reuso, reciclagem e descarte de embalagens e resíduos (LOPES, 2014).
Já a dimensão social da sustentabilidade deve ser compreendida como melhorias que envolvem a manutenção do bem-estar social no longo prazo. Está associada ao bem-estar material, bem como, à participação nas decisões coletivas no contexto de inserção dos agricultores. Além disso, podem ser considerados o acesso à saúde, bem-estar, lazer, moradia, educação, ou seja, a acessibilidade dos indivíduos que residem nas propriedades rurais a uma condição melhor de vida (STOFFEL, 2014; SILVA et al., 2016).

Neves (2016) afirma que a única forma do agronegócio brasileiro gerar resultados positivos e atender a demanda mundial crescente por alimentos é considerando a sustentabilidade no meio rural, preocupando-se com a vida das pessoas, a conservação da natureza e recursos utilizados, bem como, a manutenção dos resultados econômicos.

Nesse contexto, o acesso ao crédito é visto como uma ferramenta que pode auxiliar na produção agrícola sustentável, pautada na geração de riquezas, preservação do habitat natural e na melhoria do bem-estar dos agricultores e comunidade local (OGUNDEJl et al., 2018; OSENI; BABALOLA; ADESOYE, 2019). Conforme afirma Delgado e Bergamasco (2017) as propriedades tomadoras de crédito rural apresentam mais medidas de desenvolvimento sustentável diante as não tomadoras de crédito. Com o auxílio de recursos financeiros e acesso a informações corretas o produtor rural terá um progresso em suas atividades agropecuárias, impulsionando a qualidade de vida, agregando valor a renda por hectare cultivado e protegendo os recursos naturais, essenciais para a manutenção da vida na terra.

\section{METODOLOGIA}

Trata-se de uma pesquisa qualitativa de cunho descritivo e interpretativo, uma vez que buscou avaliar a existência de associações entre as variáveis do crédito rural e da sustentabilidade em pequenas propriedades rurais, pautando-se na descrição do fenômeno, no estabelecimento de relações entre variáveis e na compreensão da mensagem repassada (GIL, 2007; SEVERINO, 2007).

A operacionalização ocorreu por meio da realização de um estudo de campo, o qual focaliza a coleta, análise e interpretação dos resultados a partir de locais específicos (GIL, 2007). Neste caso, a pesquisa foi conduzida em uma comunidade da área rural do município de Prudentópolis, $\mathrm{PR}$, denominada "Linha Esperança".

Prudentópolis é uma cidade da região Sudeste do Estado do Paraná, situada a $212 \mathrm{~km}$ da capital Curitiba (Ver Figura 01). Sua população estimada em 2019 era de 52.241 habitantes (IBGE, 2020). A atividade econômica 
predominante é a agricultura e, como em grande parte das zonas rurais, a profissão perpetua-se de geração para geração (HAURESKO, 2015). Considerando o acesso ao crédito rural, de acordo com dados do Ministério da Agricultura, Pecuária e Abastecimento (MAPA, 2019), no plano safra 2018/2019 haviam 5.785 Declarações de Aptidão ao PRONAF (DAPs) cadastradas no município, sendo destas liberadas 1.362 operações de investimento e custeio, conforme relatório fornecido pelo Banco Central do Brasil (2019).

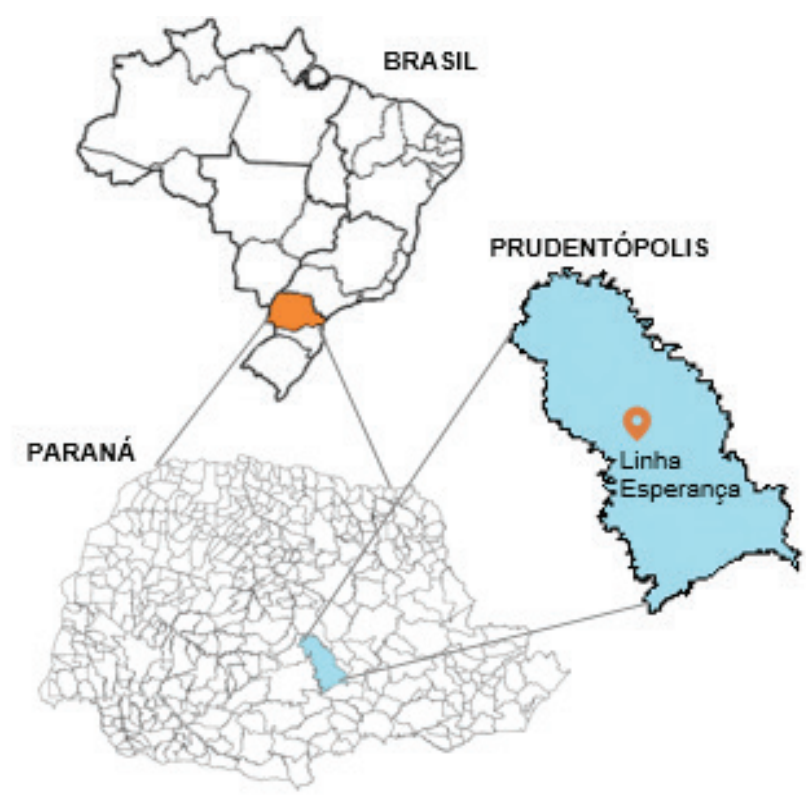

Figura 01 - Localização do município de Prudentópolis - PR Fonte: Autores (2020)

Como procedimentos de coleta de dados adotou-se técnicas de entrevista e observação. Para a realização das entrevistas empregou-se um roteiro semiestruturado, composto por 23 questões relacionadas à compreensão do perfil do produtor rural e a avaliação da utilização do crédito e o desenvolvimento das propriedades (Bloco 1), bem como direcionadas à identificação da relação entre crédito rural e sustentabilidade nos aspectos econômico, ambiental e social (Bloco 2), conforme distribuição apresentada na Tabela 01 a seguir.

\begin{tabular}{|l|l|l|}
\hline Distribuição & Objetivo/Interesse & $\begin{array}{l}\text { Questões } \\
\text { Abrangidas }\end{array}$ \\
\hline Bloco 1 & $\begin{array}{l}\text { Aspectos vinculados ao perfil } \\
\text { do produtor rural como: tempo } \\
\text { de atuação na agricultura, ativi- } \\
\text { dades desenvolvidas, tamanho } \\
\text { da propriedade e escolarida- } \\
\text { de, bem como, a avaliação da } \\
\text { relação entre a utilização do } \\
\text { crédito rural e o desenvolvi- } \\
\text { mento das propriedades. }\end{array}$ & 1 a \\
\hline
\end{tabular}

\begin{tabular}{|l|l|l|l|}
\hline Bloco 2 & $\begin{array}{l}\text { Sub- } \\
\text { bloco 1 }\end{array}$ & $\begin{array}{l}\text { Compreensão vinculada ao } \\
\text { conhecimento do conceito } \\
\text { de sustentabilidade / pro- } \\
\text { priedades sustentáveis. }\end{array}$ & 10 \\
\cline { 2 - 4 } & $\begin{array}{l}\text { Sub- } \\
\text { bloco 2 }\end{array}$ & $\begin{array}{l}\text { Aspectos relacionados ao pilar } \\
\text { econômico da sustentabili- } \\
\text { dade (existência de controle } \\
\text { de despesas, suficiência em } \\
\text { relação à renda, investi- } \\
\text { mentos na propriedade). }\end{array}$ & 11 a 15 \\
\cline { 2 - 3 } & $\begin{array}{l}\text { Aspectos relacionados ao pilar } \\
\text { bloco 3 } \\
\text { ambiental da sustentabilidade } \\
\text { (economia/preservação de } \\
\text { recursos e a relação da proprie- } \\
\text { dade com o meio ambiente) }\end{array}$ & 16 a 17 \\
\hline $\begin{array}{l}\text { Sub- } \\
\text { Bloco 4 }\end{array}$ & $\begin{array}{l}\text { Aspectos relacionados ao } \\
\text { pilar social da sustentabilidade } \\
\text { (Qualidade de vida, relação } \\
\text { com o desenvolvimento local e } \\
\text { com a comunidade abrangida) }\end{array}$ & 18 a 23 \\
\hline
\end{tabular}

Tabela 01: Detalhamento do questionário de pesquisa Fonte: Autores (2020)

O roteiro semiestruturado foi selecionado dada sua possibilidade de incluir novos questionamentos além do roteiro estabelecido, sem perder os objetivos da investigação, havendo também o incentivo para que o entrevistado fale livremente sobre assuntos de grande relevância (ZANELLA, 2009). No entanto, durante as entrevistas, não surgiram outras questões além das apresentadas no roteiro proposto.

Considerando a não possibilidade da determinação específica do número de tomadores e não tomadores de crédito rural na localidade de Linha Esperança, adotou-se a amostragem por saturação com o uso da técnica "Bola de Neve". A técnica consiste em, a partir da realização da primeira coleta de dados, inserir novos participantes em função da indicação feita pelos participantes iniciais. Neste caso, a interrupção da coleta de dados ocorre quando é atingindo o ponto de saturação, ou seja, quando novos entrevistados passam a repetir os conteúdos já obtidos em entrevistas anteriores, sem acrescentar novas informações relevantes (VINUTO, 2014).

A fim de iniciar o processo, foram realizadas visitas à três propriedades rurais da localidade, visando apresentar a proposta de estudo. No entanto, destas, apenas uma aceitou participar da pesquisa e, posteriormente, contribuiu com a indicação de propriedades vizinhas tomadoras e não tomadoras de crédito rural. Deste modo, atendendo ao critério de saturação dos dados, ao total, foram realizadas seis entrevistas com produtores rurais, sendo três tomadores de crédito rural (denominados nesse estudo pelas letras $A, D$ e E) e três não tomadores de crédito rural (denominados pelas letras $B, C$ e F), o que possibilitou o confronto de informações. 
Em relação a observação, para este estudo, foi utilizado o método de observação não participante, no qual o pesquisador presencia o fato, porém mantém-se fora de realidade, sem apresentar envolvimento com a situação (MARCONI; LAKATOS, 2009). Conforme objetivo estabelecido, foi priorizada a evidenciação do estado de conservação dos bens e questões relacionadas a impactos ambientais como a preservação das áreas verdes no entorno das propriedades, além da consideração do sentimento do entrevistado demonstrado em seus gestos.

Para análise dos dados, empregou-se a análise de conteúdo qualitativa que consiste em um conjunto de técnicas de análise com o objetivo de descrever o conteúdo das mensagens, compreendendo o sentido das comunicações, seu conteúdo e seus significados explícitos ou ocultos (BARDIN, 2011). Foram extraídas das entrevistas e observações apenas informações referentes ao problema de pesquisa. Para a análise foram utilizadas categorias de grade fechada a qual inicia-se com categorias pré-definidas através da fundamentação teórica, porém que podem ser remodeladas posteriormente a análise (VERGARA, 2010). As categorias formuladas e identificadas foram: utilização do crédito rural e a relação com o desenvolvimento das propriedades e a sustentabilidade associada ao crédito rural, esta última subdividida considerando os pilares que compõe o conceito de sustentabilidade: econômico, ambiental e social, conforme é apresentado na seção de resultados e discussões.

\section{RESULTADOS E DISCUSSÕES}

\subsection{Utilização do crédito rural e a relação com o desenvolvimento das propriedades}

Para atingir os objetivos da pesquisa, foi importante identificar o perfil do produtor rural e a sua associação com a utilização do crédito rural e o desenvolvimento de suas propriedades. Nesta seção é realizada uma breve descrição das características dos proprietários e quais suas percepções no que se refere à utilização do crédito rural.

O tempo de atuação na agricultura é relativamente elevado para todos os proprietários, compreendendo uma média de 40 anos. Em relação ao tamanho das propriedades, denota-se uma variação entre 6 a 31 hectares (em média 15,5 hectares). Esses dados são melhor discriminados na Tabela 02 a seguir:

\begin{tabular}{|l|l|l|}
\hline Entrevistado & $\begin{array}{l}\text { Tempo de atuação na } \\
\text { agricultura (anos) }\end{array}$ & $\begin{array}{l}\text { Tamanho da pro- } \\
\text { priedade (hectares) }\end{array}$ \\
\hline A & 30 & 15 \\
\hline B & 49 & 7 \\
\hline
\end{tabular}

\begin{tabular}{|l|l|l|}
\hline C & 45 & 5 \\
\hline D & 40 & 31 \\
\hline E & 35 & 29 \\
\hline F & 40 & 6 \\
\hline
\end{tabular}

Tabela 02: Tempo de atuação na agricultura e tamanho da propriedade dos casos investigados Fonte: Autores (2020)

As atividades predominantes desenvolvidas consistem no cultivo de soja, feijão e tabaco, sendo a mão de obra familiar predominante em todos os casos investigados.

É possível observar, diante do cenário pesquisado, que os proprietários tomadores de crédito avaliam o crédito rural como uma ferramenta essencial para o desenvolvimento da propriedade. Isso vai ao encontro às discussões de Ogundej et al. (2018), Linh et al. (2019), Lin et al. (2019) e Oseni, Babalola e Adesoye (2019) quando denotam a importância do crédito rural para incremento da produção, melhoria da renda familiar e aumento nos investimentos produtivos.

Os entrevistados A, D e E, que se utilizaram do crédito rural, possuem maior escolaridade entre os entrevistados, tendo completado os estudos até o $9^{\circ}$ ano do ensino fundamental. A partir das observações foi possível constatar que suas propriedades são mais desenvolvidas e os entrevistados demonstram estarem satisfeitos por conseguirem acessar o crédito rural, por meio das instituições financeiras, com objetivo de adquirir bens materiais essenciais para a evolução da produtividade.

Os entrevistados $B, C$ e $F$, os quais avaliaram o crédito rural e as instituições financeiras de maneira negativa, possuem escolaridade menor em comparação com os outros entrevistados, tendo estudado até no máximo o $4^{\circ}$ ano do ensino fundamental e suas propriedades são menos desenvolvidas que as demais.

Nesse contexto, observa-se que a escolaridade pode ser um fator determinante em relação ao acesso e a percepção relacionada ao crédito rural. Segundo Linh et al. (2019), chefes de família instruídos denotam melhores conhecimentos, habilidades agrícolas e informações sobre os mercados de crédito. Lin et al. (2019) também destacam que famílias rurais com mais escolaridade tendem a possuir maior capacidade de geração de riquezas. Ademais, sobre a questão, Assante-Addo et al. (2017) em seu estudo, atestaram que a educação do chefe de família está positivamente associada à participação dos agricultores em programas de crédito.

De um modo geral, todos os entrevistados enfatizaram as dificuldades burocráticas das instituições financeiras na busca pelo crédito rural, o que revela a necessidade de um arranjo de apoio ao crédito mais facilitado para o acesso dos agricultores (OSENI; BABALOLA; ADESOYE, 2019). 


\subsection{A sustentabilidade associada ao crédito rural}

Esta seção aborda a relação do crédito rural com as dimensões da sustentabilidade. Para atendimento deste objetivo, inicialmente, ao questionar os entrevistados de maneira geral sobre o entendimento que estes possuíam em relação a sustentabilidade, percebeu-se desconhecimento sobre o tema. Avalia-se como preocupante este aspecto identificado, pois os pequenos produtores rurais nunca tiveram instruções suficientes a ponto de compreenderem a importância que as atividades agropecuárias executadas por eles, têm para o desenvolvimento sustentável.

O estudo de Seramim e Lahgo (2016) destaca a mesma questão, ao identificar a dificuldade da propagação do termo "desenvolvimento sustentável" com a conciliação do crédito rural entre as propriedades rurais, pois os agricultores não têm acesso a informações sobre como a agricultura familiar pode ser sustentável. Para Lopes, Lowery e Peroba (2016), algo que se torna um fator inibidor para a propagação do desenvolvimento sustentável, são os próprios assistentes, técnicos, bancários e consultores que detêm pouco conhecimento sobre a questão, deixando de repassar as instruções pertinentes aos proprietários rurais.

\subsubsection{Pilar econômico}

Em relação ao pilar econômico, todos os entrevistados relataram não ter controle de suas receitas, despesas e lucratividade de maneira formal. Este elemento apresenta-se como unanimidade entre os entrevistados, porém com diferenças de percepção da possibilidade de desenvolvimento econômico da propriedade para tomadores e não tomadores de crédito.

Apesar da inexistência de controle formal sobre estes aspectos, os entrevistados A, D e E afirmam que a renda é suficiente para atender as necessidades de suas famílias, e que buscam realizar investimentos em suas propriedades para aumento da produção. A percepção de resultados positivos e o planejamento de novos investimentos demonstram que este grupo de produtores é pró ativo, quando se trata do pilar econômico do desenvolvimento sustentável de suas propriedades.

Por outro lado, o entrevistado B afirma gastar apenas o que recebe, ou seja, não tem noções de sua receita e não está disposto a investir em sua propriedade. Os entrevistados $\mathrm{C}$ e $\mathrm{F}$ também não possuem controle de seus gastos e ainda não sabem se a renda obtida é suficiente para atender suas necessidades. Citam que frequentemente faltam recursos e conseguem quitar suas dívidas somente em momentos futuros, com a comercialização de suas produções. De modo particular, o entrevistado $C$ relatou não ter capital suficiente para investir em sua propriedade, enquanto que, da parte do entrevistado $F$, há uma tentativa de desenvolvimento econômico quando afirma adquirir sementes novas anualmente para efetuar o plantio da safra, buscando aumentar a produtividade.

Considerando os relatos feitos pelos produtores rurais é possível identificar que, tomadores de crédito rural apresentam condições financeiras mais favoráveis em comparação aos não tomadores de crédito. Estes, apesar de tentativas de manter ou melhorar a situação de suas propriedades, denotam dificuldades, principalmente em relação ao controle financeiro e a realiza - ção de investimentos.

Essas constatações são também apontadas em outros estudos. Lin et al. (2019) destacam que o acesso ao crédito pode aumentar, de modo significativo, a capacidade dos agricultores rurais de atender suas necessidades financeiras e realizar investimentos produtivos. Ogundeji et al. (2018), a partir de um estudo empírico, evidenciaram um aumento líquido da receita de propriedades rurais na África de US\$ 116,608 para US\$136,894 a partir do acesso ao crédito rural. Oseni, Babalola e Adesoye (2019) também identificaram o aumento da renda de agricultores a expansão dos empreendimentos agrícolas por meio da utilização do crédito. Por sua vez, Maia, Eusébio e Silveira (2019) denotam o impacto positivo do PRONAF na produção agrícola, especialmente nas regiões mais pobres, favorecendo o aumento da renda.

As dificuldades ou resistências apresentadas para uso do crédito rural dos não tomadores estão associadas principalmente ao desconhecimento sobre o tema, baixa escolaridade e dificuldades na regularização de documentos da propriedade, o que condiz com os fatores apresentados por AsanteAddo et al. (2017) e Oseni, Babalola e Adesoye (2019) associados à decisão dos agricultores de utilizar ou não o crédito rural. Além disso, dadas condições burocráticas, o crédito rural não é alcançado por todos os produtores. Mesmo existindo políticas públicas no país para o suporte e auxílio a classe dos agricultores familiares, é perceptível que eles encontram dificuldades para atender exigências relativas aos documentos para ingressar com pedido de financiamento, além de não compreenderem as taxas de juros, considerando-as altas mesmo quando são taxas subsidiadas. Maior compreensão poderia fazer com que produtores que ainda não tomam crédito rural avaliassem a possibilidade de uso do mesmo como auxilio ao desenvolvimento de sua propriedade.

\subsubsection{Pilar ambiental}

O pilar ambiental retrata a importância da manutenção e utilização consciente de recursos da natureza. Pequenas atividades como a economia de energia elétrica ou 
recursos hídricos, assim como a preservação de áreas de vegetação, uso de defensivos agrícolas e descarte correto de resíduos demonstram a preocupação com os recursos naturais (LOPES, 2014; SILVA et al., 2016).

Sobre essa questão, os entrevistados A, C, D, E e F afirmam economizar água e energia elétrica em suas residências, bem como, durante a realização das atividades. Já o entrevistado $B$ não vê motivos plausíveis para a economia destes recursos, apesar de demonstrar preocupação com o uso correto de defensivos agrícolas. Além disso os entrevistados A, C, D e E denotam exercer suas atividades seguindo as normativas estabelecidas e instruções repassadas pelos técnicos, agrônomos e demais profissionais e fontes responsáveis pela orientação de utilização de defensivos, preservação de reservas florestais e outros pontos relevantes. O entrevistado $F$, apesar de não tomador de crédito rural, acredita ser necessária uma maior disponibilidade de recursos financeiros, bem como, uma maior área para conseguir desenvolver as atividades de maneira sustentável.

Pode-se concluir, no pilar ambiental, que a maioria dos entrevistados atua de maneira sustentável sem mesmo apresentar um conhecimento aprofundado, pois relatam um cuidado com áreas de preservação e fazem a utilização dos recursos finitos de maneira responsável. Todos revelam ainda uma preocupação com o comportamento de grandes produtores em relação ao meio ambiente. Outro aspecto relevante identificado nas entrevistas é o reconhecimento de que o uso de defensivos agrícolas deve ser efetuado de forma responsável, conforme as instruções fornecidas. Contudo, não há indícios de que estes produtores evitam sua aplicação. Este aspecto está associado a maior produtividade obtida a partir do uso destes produtos, elucidando o dilema econômico versus ambiental.

De um modo geral, para a dimensão ambiental, observam-se apenas diferenças tênues, para produtores tomadores e não tomadores de crédito no reconhecimento da economia de recursos como energia elétrica e água e na preservação das áreas verdes. No entanto, para os produtores rurais não tomadores de crédito é mais recorrente o dilema entre a preservação ambiental e o desenvolvimento econômico da propriedade.

\subsubsection{Pilar social}

No pilar social, observa-se, dentre outros fatores, a qualidade e o acesso à educação, a igualdade de direitos perante a sociedade, o reconhecimento do indivíduo sobre um mundo mais justo e a cooperação para o desenvolvimento sustentável.
Sobre a questão, os entrevistados A, D e E compreendem que a sua produção é importante para a comunidade, pois auxilia no desenvolvimento local, bem como, do agronegócio como um todo ao abastecer o mercado de alimentos e gerar movimentação econômica. Essa constatação observada na visão dos agricultores tomadores de crédito reafirma as colocações de Paula Filho, Calvi e Castro (2016), Asante-Addo et al. (2017) e Ogundeji et al. (2018), quando destacam que o acesso ao crédito contribui com o avanço do desenvolvimento agrícola local e da sociedade, garantindo a segurança alimentar, melhorando o bem-estar das famílias e reduzindo a pobreza. O estudo de Bekun, Hassan e Osundina (2019), também ressalta essa questão ao encontrar uma relação de longo prazo entre crédito agrícola e o desenvolvimento na Nigéria, assim como, Maia, Eusébio e Silveira (2019), revelam uma relação positiva entre o PRONAF e a redução das desigualdades regionais.

Já os entrevistados B, C e F sentem-se excluídos, afirmando a ausência de preocupação com a produção e com seu bem-estar social. O perfil evidenciado denota menor motivação e um não reconhecimento diante da sociedade, o que pode ser um fator influenciador no não interesse pelo acesso ao crédito rural e, consequente desenvolvimento da propriedade. Isso justifica-se, dado que o sentimento que o produtor rural carrega, transparece para seus familiares e interfere na motivação para inovar investir e produzir com a utilização consciente de recursos e gestão responsável associada com a sustentabilidade.

Ainda no pilar social, todos os entrevistados relatam sobre a falta de cursos, palestras e encontros na comunidade que os auxiliem na prática da gestão agrícola no dia a dia. Além disso, o assunto sobre cooperativas e associações é tratado com desconfiança pelos agricultores investigados. Sobre a questão, os entrevistados A, B, C, D $E$ e $F$ relatam que não existem mais associações engajadas a auxiliar as pequenas propriedades e somente algumas cooperativas do município procuram ajudá-los.

Um dos pontos principais no pilar social, consiste na ajuda mútua que pode ser estabelecida entre os pequenos produtores rurais. Quanto a isso, os entrevistados B, D, E e F relatam compartilhar equipamentos, recursos e serviços com seus vizinhos, acreditando ser uma prática vantajosa, que torna mais barata a mão de obra terceirizada. Por outro lado, os entrevistados A e C afirmaram não precisarem de seus vizinhos para exercerem suas atividades e que possuem equipamentos e maquinários suficientes, sem a necessidade de contar com empréstimos. 
O nível de educação formal recebida pelos produtores, conforme já relatado na seção anterior, é diferente para os grupos de tomadores e não tomadores de crédito rural. Os tomadores de crédito possuem maior escolaridade, sendo este elemento apontado como uma diferença do perfil social entre os grupos e que contribui para um melhor conhecimento, acesso e utilização do crédito rural (ASSANTE-ADDO et al., 2017).

Por meio da análise do pilar social é possível identificar que há uma dificuldade dos pequenos produtores rurais identificarem sua importância diante a comunidade, essencialmente considerando agricultores não tomadores de crédito. Por se tratarem de pessoas com nível de formação baixa e muito tempo de trabalho individual, ainda não percebem a essência da cooperação e tendem a se sentirem inseguros na relação com atores sociais como cooperativas e associações.

\subsubsection{Crédito rural e a sustentabilidade}

As três dimensões da sustentabilidade abordadas pelos teóricos Stoffel (2014), Silva et al. (2016), Neves (2016) e pela EMBRAPA (2018), de um modo geral, não são evidenciadas de maneira incisiva no contexto estudado, pois os agricultores ainda não detêm conhecimento do conceito, bem como, de qual modo a sustentabilidade pode estar atrelada ao desenvolvimento social, econômico e ambiental de uma comunidade. Os pequenos produtores rurais desenvolvem algumas atividades associadas aos pilares sustentáveis, mas denota-se a necessidade de que os mesmos identifiquem a sua real importância, bem como, detenham conhecimentos associados que possam ser trabalhados em suas propriedades rurais, o que poderia ser incentivado por meio de palestras, cursos e encontros comunitários, relatado como uma das necessidades pelos próprios produtores rurais.

Comparando os produtores tomadores de crédito rural e os não tomadores de crédito rural em relação aos pilares da sustentabilidade apresentados, pode-se concluir que há diferenças visíveis nas dimensões econômica e social. No entanto, no pilar ambiental diferenças são tênues e não passíveis de conclusões, sendo que todos denotam preocupações ambientais. Todavia, de um modo geral, os resultados apresentados corroboram com as afirmações de Delgado e Bergamasco (2017) no sentido de que propriedades tomadoras de crédito rural apresentam mais medidas de desenvolvimento sustentável em relação as não tomadoras de crédito. Isso pode ser representado por uma melhor condição e controle financeiro para atender as necessidades das famílias, mesmo que de modo informal, e maior predisposição para a realização de investimentos para o desenvolvimento da propriedade e incremento de produtividade, no caso dos tomadores de crédito. Além disso, denota-se uma visão otimista no que concerne à importância de sua produção para o desenvolvimento social comunitário e do agronegócio como um todo, bem como, uma tendência maior a cooperação (Ver Tabela 03).

\begin{tabular}{|l|l|l|}
\hline $\begin{array}{l}\text { Pilares da sus- } \\
\text { tentabilidade }\end{array}$ & $\begin{array}{l}\text { Tomadores de } \\
\text { crédito rural }\end{array}$ & $\begin{array}{l}\text { Não tomadores } \\
\text { de crédito rural }\end{array}$ \\
\hline Econômico & $\begin{array}{l}\text { Condições financeiras } \\
\text { mais favoráveis; postura } \\
\text { proativa; maior propen- } \\
\text { são em realizar investi- } \\
\text { mentos; maior controle } \\
\text { financeiro quanto ao } \\
\text { atendimento das } \\
\text { necessidades familiares. }\end{array}$ & $\begin{array}{l}\text { Menor controle finan- } \\
\text { realizar investimentos } \\
\text { na propriedade. }\end{array}$ \\
\hline Ambiental & $\begin{array}{l}\text { Preocupações ambien- } \\
\text { tais relacionadas ao uso } \\
\text { racional de recursos, } \\
\text { preservação de áreas } \\
\text { verdes e utilização de } \\
\text { defensivos agrícolas. }\end{array}$ & $\begin{array}{l}\text { Denotam as mesmas } \\
\text { preocupações, } \\
\text { porém o dilema } \\
\text { entre preservação } \\
\text { ambiental e desenvol- } \\
\text { vimento econômico } \\
\text { é mais presente. }\end{array}$ \\
\hline Social & $\begin{array}{l}\text { Melhor compreensão do } \\
\text { seu papel no desenvol- } \\
\text { vimento local e no agro- } \\
\text { negócio como um todo. }\end{array}$ & $\begin{array}{l}\text { Menor motivação e } \\
\text { apresenta um senti- } \\
\text { mento de não reco- } \\
\text { nhecimento diante da } \\
\text { sociedade. Menor ten- } \\
\text { dência à cooperação. }\end{array}$ \\
\hline
\end{tabular}

Tabela 03: Comparativo entre tomadores e não tomadores de crédito rural em relação ao atendimento aos pilares da sustentabilidade

Fonte: Autores (2020)

Nesse sentido, o acesso ao crédito rural é visualizado como uma importante ferramenta que pode contribuir com o desenvolvimento de uma produção agrícola sustentável (OECD, 2015; SANTOS; CEDRAZ, 2015; ASANTE-ADDO et al., 2017; OGUNDEJ et al., 2018; OSENI; BABALOLA, 2019), apesar de evidenciar a existência de um longo caminho a trilhar para que a ideia de sustentabilidade seja plenamente incorporada nos programas de acesso a crédito, reorientando normas operacionais e a conduta dos indivíduos envolvidos em busca de um desenvolvimento sustentável (GODOI; BORIGO; CAZELLA, 2016).

\section{CONSIDERAÇÕES FINAIS}

O presente estudo teve como objetivo central identificar as diferenças existentes entre pequenas propriedades rurais tomadoras de crédito e não tomadoras de crédito em relação ao desenvolvimento sustentável a partir dos pilares econômico, ambiental e social. Para isso, foi realizada 
uma pesquisa de campo em 6 propriedades rurais, sendo 3 tomadoras de crédito rural e 3 não tomadoras, no município de Prudentópolis, PR.

Os resultados denotam que o crédito rural é um fator importante para a realização de investimentos e o desenvolvimento nas propriedades rurais sob o ponto de vista dos tomadores de crédito rural, visto que investem com maior frequência e contratam financiamentos anualmente para custear a produção. Por outro lado, não tomadores de crédito não se sentem motivados para investir, a fim de melhorar condições atuais. Nesse contexto, a escolaridade pode ser um fator determinante em relação ao acesso e a percepção relacionada ao crédito rural, sendo que um melhor desenvolvimento de educação econômica seria importante para pequenos produtores rurais, para o acesso ao crédito, melhor planejamento e realização de investimentos de alto retorno.

Considerando a sustentabilidade, observou-se que há um baixo conhecimento por parte dos agricultores rurais quanto à como ela pode estar atrelada ao desenvolvimento social, econômico e ambiental da comunidade, resultado da falta de informações que poderiam ser providas por meio de palestras e cursos desenvolvidos localmente, a fim de orientar esses produtores. Desta forma, práticas sustentáveis são visualizadas de maneira pontual, no entanto, são capazes de apresentar diferenças na comparação de produtores tomadores e não tomadores de crédito rural, especialmente no que concerne aos pilares econômico e social.

Na dimensão econômica, apesar da inexistência de controle formal de receitas e despesas por parte dos produtores, observou-se que tomadores de crédito rural apresentam condições financeiras mais favoráveis, evidenciadas pelo desenvolvimento de uma postura proativa, pela maior propensão em realizar investimentos e por maior controle financeiro quanto ao atendimento das necessidades familiares atuais. Dificuldades ou resistência para a utilização do crédito rural, no que se refere aos não tomadores, estão relacionadas principalmente ao desconhecimento sobre as condições de crédito, baixa escolaridade, dificuldades na regularização de documentos da propriedade e excesso de burocracia. Nesse contexto, um maior nível de informações relacionadas poderia tornar possível a avaliação da possibilidade da utilização de crédito rural pelos não tomadores, melhorando suas condições financeiras.

No pilar ambiental, diferenças são tênues, visto que todos os entrevistados denotam preocupações ambientais relacionadas ao uso de recursos, preservação de áreas verdes e uso de defensivos agrícolas. Observa-se ainda o dilema econômico versus ambiental, elucidado com maior recorrência entre os não tomadores de crédito rural.
No que concerne ao aspecto social, observa-se que tomadores de crédito rural possuem melhor compreensão de seu papel no desenvolvimento local e do agronegócio como um todo. Por outro lado, não tomadores de crédito demonstram menor motivação e um sentimento de não reconhecimento diante da sociedade, o que pode também justificar o não interesse pelo acesso ao crédito e desenvolvimento da propriedade. Além disso, devido ao baixo nível de escolaridade e a habitualidade pelo trabaIho individual, alguns agricultores tendem a não perceberem a importância da cooperação e se sentem inseguros na relação com agentes externos.

De um modo geral, é possível concluir que pequenas propriedades rurais tomadoras de crédito rural se diferenciam das propriedades não tomadoras de crédito, tendo a influência do crédito rural associada principalmente ao grau de instrução dos indivíduos e à motivação ao conduzir a gestão de suas propriedades. Nesse sentido, o presente estudo corrobora com pesquisas anteriores já realizadas ao concluir que o perfil do pequeno produtor rural tomador de crédito denota-se mais sustentável, essencialmente considerando os pilares econômico e social, destacando o crédito rural como uma importante ferramenta que pode auxiliar em uma produção agrícola mais sustentável.

Assim, o estudo permite contribuir para acadêmicos, empresários, órgãos de apoio à agricultura familiar, cooperativas, associações e demais interessados a identificar lacunas a serem discutidas e preenchidas a fim de corroborar com o desenvolvimento sustentável de pequenas propriedades rurais. Por se tratar de um tema contemporâneo, é necessário que órgãos de apoio estejam engajados com a realização de projetos e atividades com o objetivo de conscientizar a população e fortalecer o senso crítico dos produtores, para que eles possam cada vez mais desenvolver atividades sustentáveis em seus processos.

Dadas limitações deste estudo, sugere-se para pesquisas futuras uma ampliação dos casos estudados em diferentes regiões, bem como, maior ênfase ao pilar ambiental, a fim de evidenciar comparações relacionadas principalmente a opção por tecnologias sustentáveis associadas ao crédito rural.

\section{REFERÊNCIAS}

ASANTE-ADDO, C., et al. Agricultural credit provision: what really determines farmers participation and credit rationing? Agricultural Finance Review, v. 77, n. 2, p. 239-256, jul., 2017.

BANCO CENTRAL DO BRASIL. Relatório de crédito rural contratações: quantidade e valor contratado por 
município. 2019. Disponível em: <https://www.bcb. gov.br/estabilidadefinanceira/reportmicrrural/?path=conteudo\%2FMDCR\%2FReports\%2FqvcMunicipio.rdl\&nome $=$ Quantidade $\% 20$ e $\% 20$ Valor $\% 20$ dos\%20Contratos\%20por\%2unic\%C3\%ADpio\&exibeparametros $=$ true \&botoesExportar $=$ true $>$ Acesso em: 20 abr., 2019.

. Crédito rural. 2020. Disponível em: <https:// www.bcb.gov.br/estabilidadefinanceira/creditorural> Acesso em: 27 maio 2020.

- Manual de Crédito Rural. 2020a. Disponível em: <https://www3.bcb.gov.br/mcr> Acesso em: 22 maio 2020.

BARDIN, L. Análise de conteúdo. Tradução de Luís Antero Reto e Augusto Pinheiro. São Paulo: Edições 70, 2011.

BEKUN, F. V.; HASSAN, A.; OSUNDINA, O. A. The role of agricultural credit in agricultural sustainability: dynamic causality. International Journal of Agricultural Resources, Governance and Ecology, v. 14, n. 4, p. 400417, 2019.

BLOWFIELD, M. Business and Sustainability. Oxford: UK, 2013.

CENTRO DE GESTÃO E ESTUdOS ESTRATÉGICOS CGEE. A pequena produção rural e as tendências do desenvolvimento agrário brasileiro: ganhar tempo é possível? Brasília: CGEE, 2013.

DELGADO, G. C.; BERGAMASCO, S. M. P. P. Agricultura familiar brasileira: desafios e perspectivas de futuro. Brasília: Ministério do Desenvolvimento Agrário, 2017. EMPRESA BRASILEIRA DE PESQUISA AGROPECUÁRIA EMBRAPA. Visão 2030: O futuro da agricultura brasileira. Brasília: EMBRAPA, 2018.

FOOD AND AGRICULTURE ORGANIZATION - FAO. Representante da FAO Brasil apresenta cenário da demanda por alimentos. 2017. Disponível em: <http://www.fao.org/brasil/noticias/detail-events/ en/c/901168/> Acesso em: 20 maio 2020.

. OCDE-FAO Perspectivas Agrícolas 2019-2028: Enfoque especial: América Latina. 2019. Disponível em: <http://www.fao.org/3/ca4076es/CA4076ES.pdf> Acesso em: 04 maio 2020.

GIL, A. C. Métodos e técnicas de pesquisa social. 5 ed. São Paulo: Atlas, 2007.

GODOI, T. G.; BORIGO, F. L.; CAZELLA, A. A. A sustentabilidade dos financiamentos do PRONAF para a agricultura familiar. Desenvolvimento e Meio Ambiente, v. 38, p. 637-661, ago., 2016.

GRISA, C.; SCHNEIDER, S. Políticas públicas de desenvolvimento rural no Brasil. Porto Alegre: UFRGS, 2015.

HAURESKO, C. A geografia histórica como campo de investigação para a compreensão da comunidade rural de linha esperança - Prudentópolis - Paraná. Boletim de Geografia, Maringá, v. 33, p. 1-17, 2015.

INSTITUTO BRASILEIRO DE GEOGRAFIA E ESTATÍSTICA - IBGE. IBGE cidades: Prudentópolis, PR. 2020. Disponível em: <https://cidades.ibge.gov.br/brasil/pr/ prudentopolis/panorama> Acesso em: 26 maio 2020.

LIN, L., et al. Rural credit constraint and informal rural credit accessibility in China. Sustainability, v. 11, n. 7, p. 1935-1955, abr., 2019.

LINH, T., et al. Access to rural credit markets in developing countries, the case of Vietnam: a literature review. Sustainability, v. 11, n. 5, p. 1468-1486, mar., 2019.

LOPES, D.; LOWERY, S.; PEROBA, T. L. C. Crédito rural no Brasil: desafios e oportunidades para a promoção da agropecuária sustentável. Revista do BNDES, n. 45, p. 155-196, jun., 2016.

LOPES, M. A. O futuro é bio. Hortaliças em Revista. Brasília, v. 14, 2014.

LOPES, M. A. Horizonte de 2050. Embrapa, 2018. Disponível em: <https://www.embrapa.br/busca-de-noticias/-/noticia/37534993/artigo---horizonte-de-2050> Acesso em: 26 maio 2020.

MAIA, A. G.; EUSÉBIO, G. S.; SILVEIRA, R. L. F. Can credit help small family farming? Evidence from Brazil. Agricultural Finance Review, v. 80, n. 2, p. 212-230, nov., 2019.

MARAJÓ, L. Y. B.; PLÁCIDO JÚNIOR, C. G. Desenvolvimento rural e agricultura familiar: a importância das políticas públicas de crédito rural. Nexus, v. 5, n. 9, p. 59-66, dez., 2019.

MARCONI, M. A.; LAKATOS, E. M. Fundamentos de metodologia científica. 6 ed. São Paulo: Atlas, 2009.

MINISTÉRIO DA AGRICULTURA, PECUÁRIA E ABASTECIMENTO (MAPA). Extrato DAP: Pesquisa por município. 2019. Disponível em: <http://smap14.mda. gov.br/extratodap/PesquisarDAP> Acesso em: 20 abr., 2019.

NEVES, M. F. Vai agronegócio: 25 anos cumprindo missão vitoriosa. São Paulo: CANAOESTE, 2016.

OGUNDEJI, A. A., et al. Impact of access to credit on farm income: policy implications for rural agricultural development in Lesotho. Agrekon, v. 57, n. 2, p. 152166, abr. 2018.

ORGANIZAÇÃO DAS NAÇÕES UNIDAS - ONU. World population prospects 2017. 2017. Disponível em: 
$<$ https://esa.un.org/unpd/wpp/>. Acesso em: 05 maio 2020.

ORGANIZAÇÃO PARA A COOPERAÇÃO E DESENVOLVIMENTO ECONÔMICO - OECD. OECD food and agricultural reviews: innovation, agricultural productivity and sustainability in Brazil. Paris: OECD Publishing, 2015.

OSENI; I. O.; BABALOLA, A. D.; ADESOYE, B. A. Agricultural credit policy as a panacea for sustainable food Production in Nigeria: evidence from Ogun State. Journal of Economics and Business, v. 69, n. 1-2, p. 1829, 2019.

PAULA FILHO, G. X.; CALVI, M. F; CASTRO, R. R. A. Socioeconomic analysis of rural credit and technical assistance for family farmers in the Transamazonian Territory, in the Brazilian Amazon. Journal of Agricultural Science, v. 8, n. 10, p. 177-188, 2016.

SANTOS, E. J.; CEDRAZ, J. S. A modernização da agricultura e o crédito rural: o elo de transformação da agricultura brasileira. In: VII Jornada Internacional Políticas Públicas, ed. 7, p. 6-8, Maranhão. Anais [...]. Maranhão: UFMA, 2015.

SERAMIM, R. J.; LAGO, S. M. S. Estudo das publicações sobre sustentabilidade em pequenas propriedades rurais no período de 2005 a 2015. Estudos Sociedade e Agricultura, v. 24, n. 1, p. 113-141, 2016.

SILVA, M. R., et al. Indicadores propostos na literatura nacional para avaliação de sustentabilidade na agricultura familiar. Revista Monografias Ambientais. v. 15, n. 1, p. 37-52, 2016.

STOFFEL, J. A. Construção e avaliação de indicadores de sustentabilidade para a agricultura familiar: uma análise multidimensional. 2014. 243f. Tese (Doutorado em Desenvolvimento Regional e Agronegócio) Programa de Pós-Graduação em Desenvolvimento Regional e Agronegócio, Universidade Estadual do Oeste do Paraná - Unioeste, Toledo, 2014.

SEVERINO, A. J. Metodologia do trabalho científico. São Paulo: Cortez, 2007.

VERGARA, S.C. Métodos de Pesquisa em Administração. São Paulo: Atlas, 2010.

VINUTO, J. A amostragem de bola de neve em pesquisa qualitativa: um debate aberto. Temáticas, Campinas, v. 22, n. 44, p. 203-220, 2014.

ZANELLA, L. C. H. Metodologia de Estudo e de Pesquisa em Administração. Brasília: CAPES, 2009.

\section{AUTORES}

ORCID: https://orcid.org/0000-0001-5534-3287

CAROLINA OPUCHKEVITCH | Universidade Estadual do CentroOeste (UNICENTRO) | Administração | Prudentópolis, PR - Brasil | Correspondência para: Linha Cândido de Abreu, SN, Zona Rural, Prudentópolis-PR, 84400-000 | E-mail: carolopuchkevitch@hotmail.com

ORCID: https://orcid.org/0000-0003-3358-9504

ALDO SIATKOWSKI | Universidade Estadual do Centro-Oeste (UNICENTRO) | Departamento de Administração | Irati, PR - Brasil | Correspondência para: Rua José Smolka, 25, Jardim Califórnia, Irati-PR, 84507-003 | E-mail: siatkowski. aldo@gmail.com

ORCID: https://orcid.org/0000-0003-2490-6678

FLAVIA MASSUGA, M.Sc | Universidade Estadual do CentroOeste (UNICENTRO)| Programa de Pós Graduação Interdisciplinar em Desenvolvimento Comunitário (PPGDC) | Irati, PR - Brasil | Correspondência para: Rua Miguel Agulham Júnior, 180, Jardim Virgínia, Irati-PR, 84507-208| E-mail: flavia.massuga@gmail.com

ORCID: http://orcid.org/0000-0001-8670-7282

MAURICIO JOÃO ATAMANCZUK, Dr. | Universidade Estadual do Centro-Oeste (UNICENTRO) | Departamento de Administração | Irati, PR - Brasil | Correspondência para: Rua Cap. João Alves David, 337, centro, Prudentópolis-PR, 84400-000.| E-mail: mauricioata@yahoo.com.br

\section{COMO CITAR ESTE ARTIGO}

OPUCHKEVITCH, Carolina; SIATKOWSKI, Aldo; MASSUGA, Flavia; ATAMANCZUK, Mauricio João. Crédito Rural E Sustentabilidade: Um Estudo Comparativo Em Pequenas Propriedades Rurais. MIX Sustentável, [S.I.], v. 7, n. 1, p. 61-72, dez. 2020. ISSN 24473073. Disponível em:<http://www.nexos.ufsc. br/index.php/mixsustentavel>. Acesso em: dia mês. ano. doi:https://doi.org/10.29183/2447-3073.MIX2020. v7.n1.61-72.

DATA DE ENVIO: 29/05/2020

DATA DE ACEITE: $19 / 08 / 2020$ 